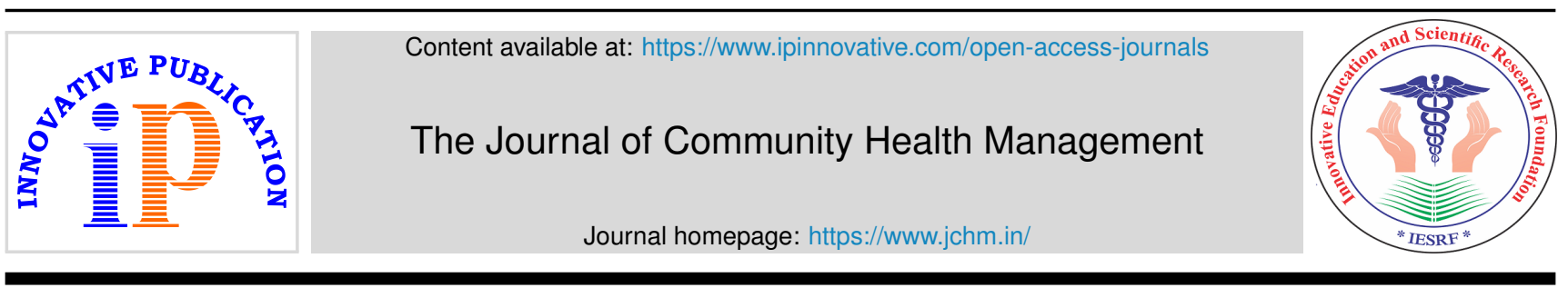

\title{
Editorial
}

\section{SARS-CoV-2 Vs Vaccines- the tug of war}

\author{
Badrinarayan Mishra ${ }^{\circledR 1, *}$ \\ ${ }^{1}$ Dept. of Community Medicine, Ruxmaniben Deepchand Gardi Medical College, Ujjain, Madhya Pradesh, India
}

A R T I C L E I N F O

Article history:

Received 25-03-2021

Accepted 01-04-2021

Available online 30-04-2021 (c) This is an open access article distributed under the terms of the Creative Commons Attribution License (https://creativecommons.org/licenses/by/4.0/) which permits unrestricted use, distribution, and reproduction in any medium, provided the original author and source are credited.
As of March 26, 2021, 10:40 GMT, the total number(globally) of SARS-CoV-2 (Coronavirus) Cases are $126,180,072$, and number of deaths are 2,769,326 with a mortality rate of $3 \% .{ }^{1}$ In terms of affected number, this pandemic has swiftly surpassed its nearest rival HIV/AIDS, which has infected nearly $100,000,000$ people since it started in 1981 and gotten established at the $4^{\text {th }}$ spot in the list of pandemics of all time. ${ }^{2,3}$

In little more than a year, this draconical demon had kept the scientific commune at their toes. Since the release of its first genome on $10^{t h}$ Jan 2020 research organizations have sweated day in and day out to find an efficient lasting solution in terms of developing vaccines. ${ }^{4}$ Thus, the era of vaccinology began and the expertise of scientists' world over have shown result. The inclusion of mRNA and nanotechnology platform has enabled us to produce vaccines at a fast pace and also to make swift alteration to them as and when needed depending on virus behaviour. To date we have 242 candidate vaccines, 66 are in phase 3 clinical trial and 11 are licensed for public use. ${ }^{5-7}$ Availability of multiple vaccines with a different mode of action is a well come step. This provides a diverse population with antibodies against different components of the virus thus making its' life difficult. In case it mutates against a particular vaccine; as been noticed for the South African variant against oxford- AstraZeneca -which is produced on viral vector platform using a chimpanzee

\footnotetext{
* Corresponding author.

E-mail address: badrinmishra@gmail.com (B. Mishra).
}

adenovirus - ChAdOx1 with actions against virus binding spike protein; it is likely to stumble in populations who have the other vaccines developed on a different platform like the Indian made Covaxin developed by using the more conventional time-tested platform of whole-virion inactivated Vero Cell-derived virus technology (coronavirus in this case) that provides a polyclonal response to many viral proteins thus enhancing the immune spectrum. The flip side of vaccines developed by this conventional platform is time tested in terms of restricting mutation and enduring protection. Some of the important examples from the past are live attenuated vaccines against human viral diseases like smallpox, poliomyelitis (Sabin oral poliovirus), measles, mumps, rubella, varicella, rotavirus, yellow fever, and some influenza vaccines and inactivated viral ones like Salk polio vaccine, hepatitis $A$, rabies, and some other influenza vaccines. ${ }^{8}$ The flop side of them is the unusually long time required for their final commissioning that usually runs into years. But the remarkable job done by the Indian scientist in developing the whole-virion inactivated Vero Cell-derived Covaxin in record time is worth mentioning. Kudos to them. It is a whole virion inactivated SARS-CoV-2 vaccine, developed from SARSCoV-2 strain (NIV-2020-770) on a CCL-81 Vero cell platform that uses $6 \mu \mathrm{g}$ with Algel-IMDG as an adjunct to boost lymphocyte response and uses components of BBV152. In addition to its claimed $81 \%$ efficacy, it has a unique 28-day open vial policy that reduces vaccine wastage by approximately $10-30 \% .^{9}$ Another vaccine developed on 
a similar platform is Russia's Gamaleya's Sputnik V vaccine that claims $92 \%$ efficacy. ${ }^{10}$ Both of them have shown promises for the mutant British strain.

In contrast to the whole-virion inactivated vaccines, the manufacturers are presently inclined to develop nucleic acid-based vaccines. They are either DNA or RNA based ones. Examples of DNA based ones are Zydus-Cadila, Inovio's INO4800 and the recent scintillating Johnson \& Johnson. Some of the important m RNA based vaccines commissioned for general use are CureVac, Moderna and BioNTech, and Pfizer. Both the nucleic acid-based vaccines act mainly by coding for the spike protein on the SARSCoV-2 virus. ${ }^{11}$

Figure 1 summarizes different types of vaccines presently available especially with context to Covid - 19 (SARS-CoV-2 virus).

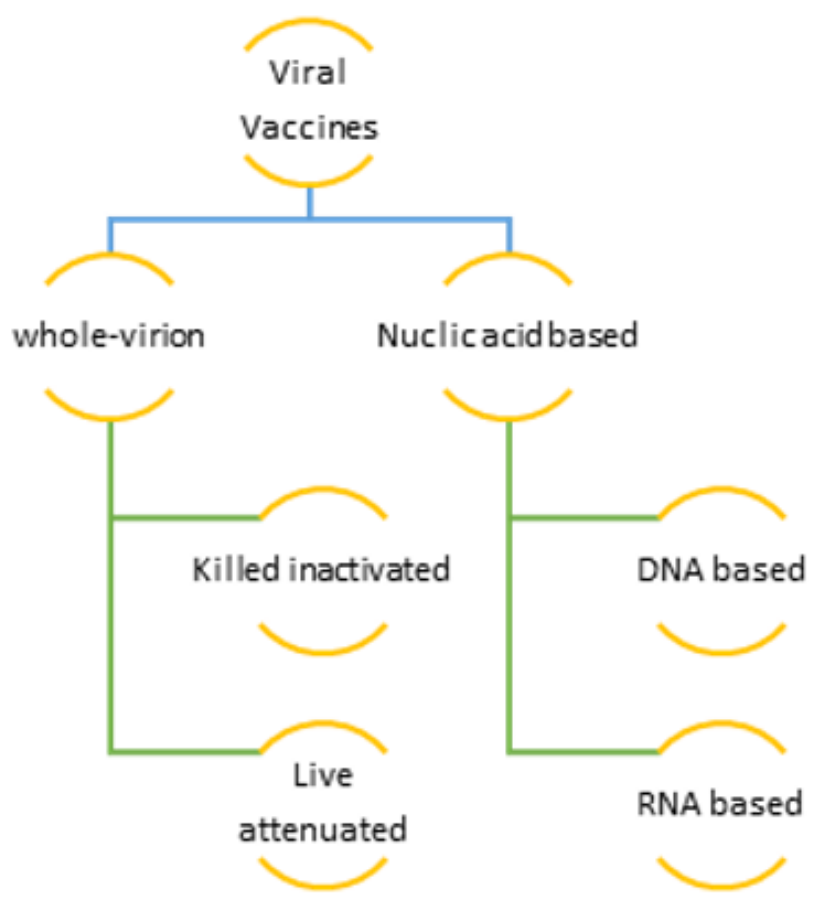

Fig. 1: Different types of vaccines for Covid -19

While the scientists are busy finding a lasting solution to the covid menace the virus appears no easy pushover. A look back in time will enlighten us on how the virus commune behaves during a pandemic and when faced with a challenge.

In contrast to the more stable DNA viruses those usually do not change or mutate, most RNA viruses because of their unstable molecule happen to mutate frequently because they lack a built-in proofreading step in their replication. When the host cell fails to correct these mistakes, the mutants have important consequences for the hosts.
To start with, a small change in the genetic composition of multiplying the virus from the original one initiates a mutation. When the virus undergoes one or more new mutations it develops into a variant. The processes of mutation and variant production are enhanced when the virus has an open playing field. In the case of SARS-CoV2 , the ground is ripe for mutation and variant development. It has all the necessary ingredients, in form of a virgin population, its high infectivity rate ( $R$ nought value) and high paced global mobility. Most viral mutations are nonconsequential. But they pose a real threat when the mutation happens in the genetic material of the virus that alters the virus's properties in terms of transmission or disease severity. To catch the mutant variants early genetic sequencing of the virus is a fundamental prerequisite. Catching them young and acting on the decoded information is key to develop modify vaccines in time.

The first modified variant of SARS-CoV-2 was reported in Jan-Feb 2020. This D614G variant which has a spike protein substitution enhanced the infectivity of the virus and by June 2020 was the leading one navigating the globe almost making the original Wuhan strain non-existent. ${ }^{3,12}$

The next important one was SARS-CoV-2 VOC (Variant of Concern) 202012/01 UK (United Kingdom) variant. This fast-spreading strain took over the entire UK within 15 days (14 ${ }^{\text {th }}$ Dec 2020 to $26^{\text {th }}$ Dec 2020). Though it was highly infectious its virulence is not yet established. ${ }^{13-16}$

The most opulent variant to date is the South Africa 501Y.V2. This phylogenetically different variant is in news because of its higher viral load and the speed at which it has replaced the previously circulating lineages. Its increased transmissibility and resistance to many m RNA based vaccines are the cause of huge concern. Since its genomic report went public on 18 December labs across the globe are working on developing modified vaccines to tackle this issue. ${ }^{17,18}$

The plethora of vaccines is a boon to fight against the virus especially, when it is mutating fast and wide. The sooner they are available under the cafeteria umbrella at the global platform and more and more eligible populace gets the jabs the better poised we will be in dealing with the rampaging demon. A diverse mix of the population with antibodies produced against different viral components and by different modalities will be a potent shield against the mutant strains thereby hopefully cornering the virus to natural elimination.

Besides, we have to keep on adapting and adjusting our vaccine production platform by incorporating more than one strain as and when in development, use booster shots to enhance immune response and stick to covid appropriate norms and nonpharmacological management protocols like physical distancing in terms of travel restrictions from mutant locations. ${ }^{19}$ All these measures are in all like hood will strengthen our fight against the virus in time to come. 


\section{Conflict of Interest}

None.

\section{References}

1. WHO Health Emergency Dashboard, WHO (COVID-19) Homepage. Source: World Health Organization.

2. Global HIV \& AIDS statistics - 2020 fact sheet, UNAIDS. Available from: www.unaids.org.

3. Mishra B, Mishra B, Mishra G, Sinha ND. Pandemic Dynamics, the three Waves of COVID-19 and the Way Ahead. J Adv Res Med Sci Tech. 2021;8(1):13-8.

4. Williams TC, Burgers WA. SARS-CoV-2 evolution and vaccines: cause for concern? Lancet Respir Med. 2021;9(4):333-5. doi:10.1016/s2213-2600(21)00075-8.

5. Athavale AV. The Covid-19 Vaccine. J Adv Res Med Sci Tech 2021;8(1):29-35. 101:10243212394-6539202103.

6. COVID-19 Vaccine Rollout in India: State by State. Available from https://geographicinsights.iq.harvard.edu/IndiaVaccine.

7. COVID-19 vaccine tracker. Available from: https://www.raps.org/ news-and-articles/news-articles/2020/3/covid-19-vaccine-tracker.

8. Minor PD. Live attenuated vaccines: Historical successes and current challenges. Virology. 2015;479-480:379-92. doi:10.1016/1.virol.2015.03.032

9. Ella R, Reddy S, Jogdand H, Sarangi V, Ganneru B, Prasad S. Safety and immunogenicity of an inactivated SARS-CoV-2 vaccine, BBV152: interim results from a double-blind, randomised, multicentre, phase 2 trial, and 3-month follow-up of a doubleblind, randomised phase 1 trial. Lancet Infect Dis. 2021;(21):70. doi:10.1016/s1473-3099(21)00070-0.

10. Available from: https://www.historyofvaccines.org/content/articles/ vaccine-development-testing-and-regulation.

11. Baraniuk C. Covid-19: What do we know about Sputnik V and other Russian vaccines? BMJ. 2021;372:n743. do1:10.1136/bm].n/43.

12. Mas V, Nair H, Campbell H, Melero JA, Williams TC. Antigenic and sequence variability of the human respiratory syncytial virus $\mathrm{F}$ glycoprotein compared to related viruses in a comprehensive dataset. Vaccine. 2018;36(45):6660-73. doi:10.1016/j.vaccine.2018.09.056

13. Weisblum Y, Schmidt F, Zhang F, DaSilva J, Poston D, Lorenzi JCC, et al. Escape from neutralizing antibodies by SARS-CoV-2 spike protein variants. eLife. 2020;9:e61312. 10i:/0.7554/eLife.6/312.

14. Andreano E, Piccini G, Licastro D. SARS-CoV-2 escape in vitro from a highly neutralizing COVID-19 convalescent plasma. bioRxiv.

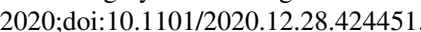

15. Liu Z, VanBlargan LA, Rothlauf PW, Bloyet LM, Chen RE, Stumpf S, et al. Landscape Analysis of Escape Variants Identifies SARS-CoV2 Spike Mutations that Attenuate Monoclonal and Serum Antibody Neutralization. SSRN Electron J. 2021 101:02139/ssrn.3725763

16. Tegally H, Wilkinson E, Giovanetti M, Iranzade A. Emergence and rapid spread of a new severe acute respiratory syndrome-related coronavirus 2 (SARSCoV-2) lineage with multiple spike mutations in South Africa. medRxiv. 2020;

17. Cele S, Gazy I, Jackson L, Hwa SH, Tegally H, Lustig G, et al. Escape of SARS-CoV-2 501Y.V2 variants from neutralization by convalescent

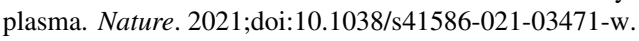

18. Wibmer CK, Ayres F, Hermanus T, Hermanus T, Madzivhandila M, Kgagudi $\mathrm{P}$, et al. SARS-CoV-2 501Y.V2 escapes neutralization by South African COVID-19 donor plasma. Nat Med. 2021;27:622-5.

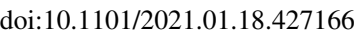

19. Athavale AV. Physical Distancing, Hand Hygiene and Masks. $J A d v$ Res Med Sci Tech. 2020;7(3):1-3.

\section{Author biography}

Badrinarayan Mishra, Professor (1) https://orcid.org/0000-0001-69560469

Cite this article: Mishra B. SARS-CoV-2 Vs Vaccines- the tug of war. J Community Health Manag 2021;8(1):1-3. 